\title{
PCR identification of Mycobacterium tuberculosis complex in a clinical sample from a patient with symptoms of tuberculous spondylodiscitis
}

M.A. Ribeiro ${ }^{1}$ A.S. Barouni $i^{3,4}$ C.J. Augusto ${ }^{3}$, M.V.S. Augusto ${ }^{2}$, M.T.P. Lopes ${ }^{4}$ and C.E. Salas ${ }^{4}$

\author{
${ }^{1}$ Hospital Maria Amélia Lins, ${ }^{2}$ Hospital Eduardo de Menezes, \\ Fundação Hospitalar de Minas Gerais, Belo Horizonte, MG, Brasil \\ ${ }^{3}$ Fundação Ezequiel Dias, Laboratório Central de Saúde Pública de Minas Gerais, \\ Belo Horizonte, MG, Brasil \\ ${ }^{4}$ Departamento de Bioquímica e Imunologia, Instituto de Ciências Biológicas, \\ Universidade Federal de Minas Gerais, Belo Horizonte, MG, Brasil
}

\section{Correspondence}

C.E. Salas

Departamento de Bioquímica

e Imunologia

ICB, UFMG

Av. Antônio Carlos, 6627

31270-901 Belo Horizonte, MG

Brasil

Fax: +55-31-3499-2646

E-mail: cesbufmg@mono.icb.ufmg.br

Received March 13, 2006

Accepted August 29, 2006

....................

\begin{abstract}
A 42-year-old male complaining of thoracic spine pain was admitted to the hospital for evaluation. An X-ray and computer tomography of the thoracic spine showed spondylodiscitis of the L3 lumbar and L2L3 intervertebral disk. The tuberculin skin test (PPD) was strongly positive. A radioscopy-guided fine needle aspirate of the affected area was cultured but did not reveal the cause of the disease. Two biopsy attempts failed to reveal the cause of the disease by culturing or by acid-fast-resistant staining (Ziehl Neelsen) of the specimens. A third biopsy also failed to detect the infectious agent by using microbiological procedures, but revealed the presence of a 245-bp amplicon characteristic of the Mycobacterium tuberculosis complex after PCR of the sample. The result demonstrates the efficacy of PCR for the identification of $M$. tuberculosis in situations in which conventional diagnosis by culturing techniques or direct microscopy is unable to detect the microorganism. Following this result the patient was treated with the antituberculous cocktail composed by rifampicin, pirazinamide and isoniazid during a six-month period. At the end of the treatment the dorsalgia symptoms had disappeared.
\end{abstract}

Spondylodiscitis is a rare inflammatory disorder of the intervertebral discs and the adjacent vertebral bodies. In 25 to $33 \%$ of cases, spondylodiscitis is associated with an epidural abscess $(1,2)$. Spondylodiscitis may occur spontaneously or as a result of spinal surgery. Patients with diabetes mellitus, lung or systemic infection, drug abuse, chronic renal failure, alcoholism, malignancy, and those undergoing dialysis, transplantations,
Key words - Spondylodiscitis

- Tuberculosis

- Polymerase chain reaction

- Mycobacterium tuberculosis complex or whose immune system is depressed are more frequently affected. Microbial agents that most frequently cause spondylodiscitis are Staphylococcus, Brucella, Salmonella, and Mycobacterium tuberculosis, but many other microorganisms have also been shown to be associated with this condition $(3,4)$.

Tuberculosis (TB) is endemic in most developing countries. However, a resurgence of TB has also been reported in the past 
decades in developed countries, not only affecting the lungs, but also extrapulmonary sites, e.g., the vertebral column.

The oldest record of vertebral TB dates back to the pre-dynastic Egyptian era, 5400 BC (5). Vertebral TB is most often found in the lower thoracic and upper lumbar regions. Its early detection is of major importance since TB kills more than any other infectious disease (6). Nonpulmonary osteoarticular TB represents about $10 \%$ of all cases, the spine being the most frequent target (7). Diagnosis of nonpulmonary TB is often difficult; clinical findings are usually not-specific and radiological features may mimic those of other bacterial, fungal, inflammatory, and neoplastic diseases.

Although a presumptive diagnosis of vertebral TB can be made based on patient history and/or clinical and radiological information, the final diagnosis depends on bacterial identification by culture or acidfast staining.

However, recognition and understanding of the radiological findings may help with the diagnosis. Two distinct patterns of vertebral TB may be observed: the classic finding of spondylodiscitis, characterized by destruction of two or more contiguous vertebral opposed end plates and disk infection. The second pattern, increasing in frequency, is an atypical form of spondylitis without disk involvement. A positive culture or histopathologic analysis of computed tomography-guided needle aspiration or biopsy specimens is required in the absence of pulmonary manifestations of $\mathrm{TB}$ for a definitive diagnosis and adequate treatment. A persistent and even invasive diagnostic work-up is needed for the proper and prompt management of these patients. Even then, percutaneous approaches to obtain material from the area with the infection have a sensitivity of $72 \%$, though specificity reaches $94 \%$ (8). Direct examination of smears for acid-fast bacilli is the most rapid method for the detection of mycobacteria, but it lacks speci- ficity and requires a relatively large number of microorganisms in the specimen to be analyzed. The alternative culturing procedure is time consuming and requires about one month to identify the presence of bacilli.

On the basis of our experience identifying M. tuberculosis (9), we successfully applied the polymerase chain reaction (PCR) to characterize the bacteria in this clinical situation.

A 42-year-old male was admitted to the hospital on October 29th, 2004, with symptoms of acute dorsalgia and irradiation to the lower limbs. The patient reported weight loss and absence of fever episodes or other complaints. His past medical history was negative for $\mathrm{TB}$ but the patient admitted being an injectable drug user between 1980 and 1990. Clinical examination confirmed the lumbar pain during palpation and the absence of evident neurological alterations.

The X-ray of the lumbar spine showed partial destruction of L2-L3 and narrowing of the disc interspace (Figure 1). Computer tomography of the lumbar spine confirmed the damage to L2-L3 compromising the vertebral body (Figure 1). The tuberculin skin test (PPD) was strongly positive $(15 \mathrm{~mm})$ and serum was negative for HIV.

The secretion obtained on November 26, 2004 from a percutaneous biopsy at L2-L3 did not show granulomas, necrosis or neoplastic cells nor did it yield bacteria following culture assay. The acid-fast stain test was also negative.

A second open biopsy performed three weeks later produced a similar negative result. A third percutaneous biopsy obtained on January 14, 2005 from the right latero-posterior body of L3 and the L2-L3 junction resulted in the absence of bacterial colonies after culturing in Lowenstein Jensen medium (Difco, Le Port de Claix, France) and a negative reaction following Ziehl-Neelsen staining. However, PCR applied directly to the specimen using IS6110 primers produced a 245-bp amplicon (10) featured by the M. tuberculosis complex 
(Figure 2). The sample was amplified in a 25$\mu \mathrm{L}$ reaction mixture containing $50 \mathrm{mM} \mathrm{KCl}$, $10 \mathrm{mM}$ Tris-HCl, $\mathrm{pH} 8.3,1.5 \mathrm{MgCl}_{2}, 0.01 \%$ gelatin, $0.2 \mathrm{mM}$ each dNTP (Invitrogen Life Technologies, Carlsbad, CA), 1.5 U Taq polymerase (Amersham Bioscience, Buckinghamshire, UK), and 30 pmol of each primer INS1INS2 (Invitrogen). The reaction was subjected to amplification using the following program: 5 min initial denaturation at $95^{\circ} \mathrm{C}$, followed by 35 cycles (each cycle was $95^{\circ} \mathrm{C}$ for $1 \mathrm{~min}$; $68^{\circ} \mathrm{C}$ for $1 \mathrm{~min} ; 72^{\circ} \mathrm{C}$ for $1 \mathrm{~min}$ ) and $10 \mathrm{~min}$ extension at $72^{\circ} \mathrm{C}$ in an $\mathrm{MJ}$ termocycler. Five microliters of PCR was electrophoresed on a 6\% PAGE in buffer containing $82 \mathrm{mM}$ Tris$\mathrm{HCl}, \mathrm{pH} 7.5,89 \mathrm{mM}$ borate and $2 \mathrm{mM}$ EDTA for $1 \mathrm{~h}$ at $150 \mathrm{~V}$ at room temperature and stained with silver nitrate. Control experiments without DNA added to the reaction mix did not show amplification. Following this result, antibiotic therapy was initiated with isoniazid, rifampin and pyrazinamide for 2 months followed by isoniazid and rifampin for 4 months. After 6 months, the patient showed a marked improvement of symptoms.

The failure of microbiology to detect and identify the infectious agent after successive attempts to inoculate samples removed from the infected area is noteworthy. A similar situation was recently described by Rafailidis et al. (11) for a case of multidrug-resistant tuberculous spondylodiscitis. Although prior studies $(12,13)$ have shown that PCR is an efficient tool to confirm a diagnosis of tuberculous spondylodiscitis, we are not aware of any report describing the failure to detect the infectious agent by the traditional microbiological or acid-fast procedures, leaving PCR as the only alternative. We conclude that PCR remains a valuable option for rapid identification of the M. tuberculosis complex when other microbiological procedures fail and the clinical symptoms suggest the presence of the microorganism.

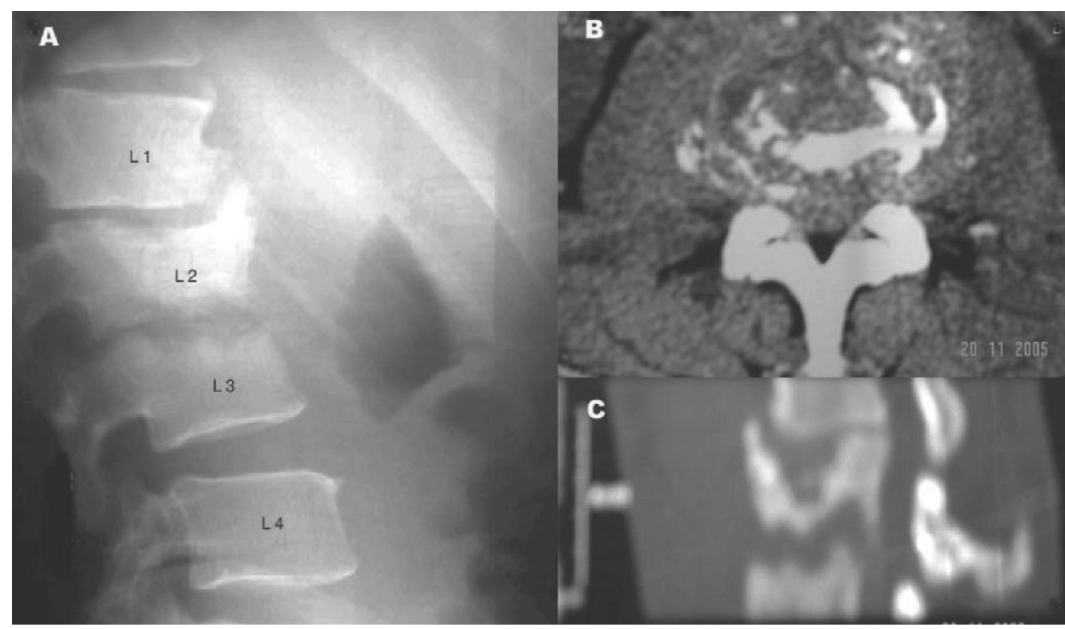

Figure 1. A, Lumbar X-ray destruction of adjacent vertebral bodies (L2-L3) and the intervening disk. $B$ and $C$, Computed tomography showing disruption of vertebral bodies (L2-L3).

Figure 2. Detection of Mycobacterium tuberculosis complex in clinical samples by PCR amplification with IS6110 primers. The amplicons were analyzed by $6 \%$ PAGE and silver stained. Lane 1, Secretion aspirate; lane 2, bone fragment; lane 3, M. tuberculosis H37Rv-positive control; lane 4, negative control for sample DNA extraction; lane 5, PCR minus DNA (negative control); lane 6, 100-bp DNA standard.

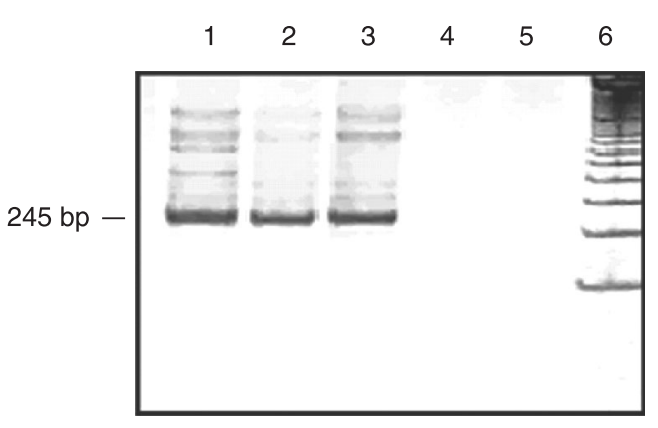

\section{References}

1. Kapeller P, Fazekas F, Krametter D, Koch M, Roob G, Schmidt R, et al. Pyogenic infectious spondylitis: clinical, laboratory and MRI features. Eur Neurol 1997; 38: 94-98.

2. Maiuri F, laconetta G, Gallicchio B, Manto A, Briganti F. Spondylodiscitis. Clinical and magnetic resonance diagnosis. Spine 1997; 22 : 1741-1746.

3. Mackenzie AR, Laing RB, Smith CC, Kaar GF, Smith FW. Spinal epidural abscess: the importance of early diagnosis and treatment. $J$
Neurol Neurosurg Psychiatry 1998; 65: 209-212.

4. Weber U, Morf MH, Gubler JG, Altwegg M, Maibach RC. Spondylodiscitis as the first manifestation of Whipple's disease - a removal worker with chronic low back pain. Clin Rheumatol 2003; 22: 443446.

5. Crubezy E, Ludes B, Poveda JD, Clayton J, Crouau-Roy B, Montagnon D. Identification of Mycobacterium DNA in an Egyptian Pott's disease of 5,400 years old. C R Acad Sci III 1998; 321: 941-951. 
6. WHO (World Health Organization). Tuberculosis, a global emergency. Geneva: WHO report on the TB epidemic; 1994.

7. Stuart D. Local osteo-articular tuberculosis complicating closed fractures: report of two cases. J Bone Joint Surg Br 1976; 58: 248-249.

8. Fouquet B, Goupille P, Gobert F, Cotty P, Roulot B, Valat JP. Infectious discitis diagnostic contribution of laboratory tests and percutaneous discovertebral biopsy. Rev Rhum Engl Ed 1996; 63: 24-29.

9. Barouni AS, Augusto C, Queiroz MV, Lopes MT, Zanini MS, Salas CE. BCG lymphadenopathy detected in a BCG-vaccinated infant. Braz J Med Biol Res 2004; 37: 697-700.

10. van Embden JD, Cave MD, Crawford JT, Dale JW, Eisenach KD, Gicquel B, et al. Strain identification of Mycobacterium tuberculosis by DNA fingerprinting: recommendations for a standardized meth- odology. J Clin Microbiol 1993; 31: 406-409.

11. Rafailidis PI, Avramopoulos I, Sapkas G, Falagas ME. Multidrugresistant tuberculous spondylodiscitis: need for aggressive management and drug susceptibility testing of Mycobacterium tuberculosis isolates. J Infect 2006; 52: e35-e37.

12. Cabral MML, Azevedo BCCA, Montenegro LML, Montenegro RA, Lima AS, Schindle HC. Espondilite tuberculosa em adolescente. J Bras Pneumonol 2005; 31: 261-264.

13. Wang JY, Lee LN, Chou CS, Huang CY, Wang SK, Lai HC, et al. Performance assessment of a nested-PCR assay (the RAPID BAPMTB) and the BD ProbeTec ET system for detection of Mycobacterium tuberculosis in clinical specimens. J Clin Microbiol 2004; 42: 4599-4603. 